\title{
ANALISIS KATA men̄̄ BERDASARKAN SURAT 1 YOHANES
}

\author{
Nyoman Lisias Fernand Dju ${ }^{1) *}$ \\ 1) Alumni Magister Teologi Sekolah Tinggi Theologia Jaffray \\ ${ }^{*}$ Penulis korespondensi: nyfsiasdju@yahoo.com
}

\begin{abstract}
Abstrak
Tujuan penulisan ini adalah mengetahui makna kata menō dalam surat 1 Yohanes melalui pendekatan studi eksegesis yaitu analisis leksikal, analisis gramatikal, analisis konteks dan analisis historis. Perjanjian Baru menggunakan kata menō digunakan dalam hubungan dengan Allah, berarti menekankan sifatnya, sementara dalam hubungan dengan doktrin Kristen, kata ini digunakan secara kiasan menunjuk kepada ketetapan hidup sebagai umat yang diselamatkan. Secara gramatikal, bentuk yang menyatakan bahwa suatu tindakan (peristiwa) sedang terjadi, subjeknya melakukannya secara aktif dan tindakan/peristiwa itu merupakan suatu realitas. Penulis surat ini, Yohanes menyatakan dengan serius bahwa hal yang paling mungkin bagi seseorang untuk tinggal dalam Anak dan Bapa adalah harus tetap tinggal di dalam firman yang "telah kamu dengar dari mulanya." Sedangkan pendekatan analisis konteks arti menō adalah orang yang lahir dari Allah dan berada di dalam Dia memiliki potensi untuk menjauhkan diri dari dosa karena benih ilahi tinggal tetap di dalamnya dan karena mereka mengenal Dia. Dalam konteks historis penggunaan kata menō yang di dalamnya terkandung pengajaran dan nasihat yang mendasar mengenai doktrin dan praktika hidup Kristen jelas menunjukkan bahwa secara historis teologis kata ini merupakan kata yang penting dalam pergumulan iman dan perkembangan doktrin dalam komunitas Kristen mula-mula.
\end{abstract}

Kata-kata kunci: menō, tinggal, Yohanes, Kristus, eksegesis, leksikal, konteks, 1 Yohanes.

The purpose of this writing is to understand the meaning of the word meno in the first letter of John through the approach of exegetical study-that is, lexical analysis, grammatical analysis, contextual analysis, and historical analysis. The New Testament uses the word menō in relation to God to emphasize His nature. At the same time, in relation to Christian doctrine, this word is used figuratively to point to the life statutes of the people of God who have been saved. Grammatically, the form of the word used states that an action (event) is in progress, the subject is actively doing the action, and the action/event is a reality. The writer of this letter, John, states with seriousness, that the most important possible thing for someone to live in the Son and the Father, is to keep living in His Word that "you have heard from the beginning." Meanwhile, from the approach of contextual analysis, the meaning of menō is that a person 
who has been born from God and abides in Him has the potential to abstain from sin because of the divine seed living in him/her, and because they are close to Him. From an historical context, the use of the word meno consists of teaching and counsel that is foundational to Christian doctrine and practical Christian living. It is clear from an historical theological perspective that this word was very important in the struggles of faith and the development of Christian doctrine in the early Christan community.

Keywords: menō, abide, John, Christ, Exegesis, Lexical, Context, 1 John

\section{Pendahuluan}

Alkitab menggunakan berbagai narasi, argumentasi, ilustrasi atau kiasan-kiasan bahkan kata-kata tertentu untuk menjelaskan dan menyatakan hal-hal mendasar yang berkaitan dengan karya keselamatan itu. Meski terkadang terdapat kata-kata yang sulit, ini bukanlah berarti bahwa setiap kata-kata dalam Alkitab merupakan kata-kata yang asing yang tidak pernah digunakan atau dikenal oleh manusia, tetapi sebaliknya, kata-kata itu merupakan kata-kata yang biasa dipakai, dapat dimengerti dan dipahami oleh manusia. ${ }^{1}$

Penulis surat 1 Yohanes memiliki kekhasan dalam tulisannya. Secara keseluruhan, Injil Yohanes dan surat 1 Yohanes memiliki kesamaan dalam penggunaan kata-kata. Artinya, kata-kata yang sering muncul atau digunakan dalam Injil Yohanes dan surat 1 Yohanes memiliki keterkaitan dan kemiripan yang sangat dekat. John Drane menyatakan bahwa ada banyak persamaan yang dekat antara Injil Yohanes dan Surat 1 Yohanes. Keduanya memakai bahasa dengan cara yang sama, mengkontraskan antara terang dan gelap, kehidupan dan kematian, kebenaran dan kesesatan, semuanya ditemukan baik dalam Kitab Injil maupun suratnya. ${ }^{2}$

Dari sekian banyak kesamaan, khususnya dalam hal penggunaan kata, salah satu kata yang sangat menonjol dan sering digunakan baik dalam Injil maupun dalam surat 1 Yohanes adalah kata menō. Kata ini digunakan 118 kali dalam seluruh Perjanjian Baru, 40 kali dalam Injil Yohanes dan 24 kali dalam Surat 1 Yohanes. ${ }^{3}$ Ini berarti, Rasul Yohanes sebagai penulis kitab Injil dan Surat 1 Yohanes menggunakan kata ini dalam tulisannya sebanyak 64 kali (lebih banyak dari pada Paulus dalam

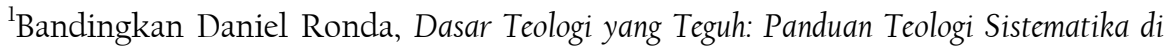
Perguruan Tinggi (Makassar: Sekolah Tinggi Theologia Jaffray, 2013), 18-19.

2 John Drane, Memahami Perjanjian Baru: Pengantar Historis - Teologis (Jakarta: BPK Gunung Mulia, 1996), 519.

3 Hasan Sutanto, Perjanjian Baru Interlinear Yunani - Indonesia dan Konkordansi Perjanjian Baru: Jilid II: Konkordansi Perjanjian Baru (Jakarta: Lembaga Alkitab Indonesia, 2002), 510.
} 
tulisan-tulisannya). Uniknya, surat 1 Yohanes yang lebih singkat/pendek dari Injil Yohanes menggunakan setengah dari banyaknya pengunaan kata tersebut dalam Injil. Memerhatikan keunikan ini, penulis berkeyakinan bahwa terdapat makna atau pengajaran teologis bagi orang Kristen yang hendak dinyatakan oleh Rasul Yohanes dalam tulisannya. Para ahli Perjanjian Baru mengakui bahwa Yohanes mampu memberi pemahaman dan teologi yang dalam meskipun hanya dengan memakai istilah atau kata yang sederhana. ${ }^{4}$

Pentingnya pemahaman yang memadai mengenai kata menō telah disadari oleh seorang rohaniawan terkemuka Andrew Murray. Ia mengatakan bahwa:

Yang ditakutkan, makna kata ini sangat tersembunyi - bagi banyak pengikut Yesus yang sungguh-sungguh. Sementara percaya pada Juruselamat mereka untuk pengampunan dan pertolongan, dan berusaha menanti-Nya sampai tingkat tertentu, mereka hampir tidak menyadari kedekatan kesatuan, keintiman persekutuan dan keindahan kesatuan hidup yang Dia mengundang mereka untuk mengalaminya ketika Dia berkata, "Tinggallah dalam Aku." Ini bukan hanya kehilangan yang tak terkatakan bagi mereka, tetapi gereja dan dunia juga mengalami kehilangan. ${ }^{5}$

Berdasarkan pandangan ini, maka dapat ditegaskan bahwa kata menō perlu diselidiki dan dipelajari dengan seksama agar dapat menghasilkan atau merumuskan pemahaman yang memadai yang berguna untuk pertumbuhan iman orang Kristen masa kini. Mereka yang kurang atau tidak memiliki pemahaman akan sebuah pemahaman dari kebenaran yang diajarkan Alkitab diharapkan dapat memiliki pengertian yang benar yang berguna bagi perjalanan dan pengalaman rohani dalam mengikut Yesus.

\section{Analisis Kata $\mu \varepsilon \nu \omega($ men⿳亠口) dalam Surat 1 Yohanes}

\section{Genre Sastra Surat 1 Yohanes}

Menurut Sitompul dan Beyer, dalam Perjanjian Baru ada tiga jenis sastra besar (genre), yaitu naratif (narrative), tulisan (epistle) dan wahyu (apocalypse). ${ }^{6}$ Surat 1 Yohanes termasuk dalam kategori tulisan (epistle). Beberapa ahli Perjanjian Baru memperdebatkan bahwa 1

\footnotetext{
${ }^{4}$ Walter A. Elwell, ed., Evangelical Dictionary of Theology (Michigan: Baker Book House, 1989), 586.

${ }^{5}$ Andrew Murray, Tinggal di Dalam Kristus (Jakarta: Light Publishing, 2014), 7.

${ }^{6}$ A. A. Sitompul dan Ulrich Beyer, Metode Penafsiran Alkitab (Jakarta: BPK Gunung Mulia, 2012), 227.
} 
Yohanes tidak dapat dikatakan sebagai suatu surat sebagai mana lazimnya, ${ }^{7}$ karena struktur dokumen ini hampir tidak memenuhi unsurunsur sebuah surat sebagaimana mestinya. ${ }^{8}$

Gaya penyusunan 1 Yohanes adalah paraklese indicative. Dalam Perjanjian Baru, surat-surat kiriman (epistolary literature) pada umumnya memakai pola paranese imperative dan atau paraklese indicative. ${ }^{9}$ Dalam kaitannya dengan penggunaan kata meno, cara penyusunan yang bersifat paranese indicative dapat diterima karena terbukti bahwa nas-nas tersebut lebih sering menggunakan modus indicative.

Ditinjau dari sudut retoris, pandangan terbaik yang diakui sehubungan dengan genre sastra surat ini adalah bahwa surat ini ( dan 2 Yohanes) merupakan sebuah homili deliberatif, sementara 3 Yohanes bersifat epideiktik. ${ }^{10}$ Sebagai sebuah tulisan deliberatif (yang berusaha meyakinkan pembaca untuk melakukan sesuatu) maka sangat sesuai jika surat ini lebih cenderung memakai modus indicative (linear), walau terdapat juga modus lainnya dalam surat ini.

Konteks kehidupan (setting in life/sitz im leben) dari surat ini adalah tradisi apologetis-parakletis. Hal ini dapat dilihat dalam karakter surat ini yang menyatakan kebenaran dengan cara yang bersifat apologia (persuasif). Dalam melawan dan membantah ajaran sesat yang dihadapi, penulis surat ini memilih untuk menyatakan hal-hal positif mengenai kebenaran yang asasi, jauh dari sikap kasar dan arogan. Nuansa kedewasaan iman dan keyakinan penulis mengenai kebenaran itu dalam surat sangat kuat. Dengan kata lain, penulis memilih mempertahankan keyakinannya akan kebenaran dengan berusaha memahami dan mendalami dasar kebenaran itu dalam konsep-konsep yang fundamental dari pada menyerang kesesatan dengan cara-cara yang frontal dan profan.

\section{Struktur Surat 1 Yohanes}

Ahli-ahli Perjanjian Baru tidak memiliki kesepakatan yang sama mengenai struktur surat ini. Masing-masing memiliki pola dan prinsip sendiri dalam merumuskan struktur surat tersebut. Hal ini dapat dimaklumi mengingat alur surat ini yang memang tidak linear tetapi

\footnotetext{
${ }^{7}$ Bandingkan Everret F. Harrison, Introduction to The New Testament (Michigan: Wm. B. Eerdmans Publishing Company, 1965), 414.

${ }^{8}$ Struktur surat lihat Hasan Sutanto, Prinsip dan Metode Penafsiran Alkitab (Malang: Literatur SAAT, 2011), 416-418.

9 John Hayes dan Carl R. Holladay, Pedoman Penafsiran Alkitab (Jakarta: BPK Gunung Mulia, 1996), 56.

${ }^{10}$ William W. Klein, Craig L. Blomberg, and Robert L. Hubbard, Introduction to Biblical Interpretation (Malang: Literatur Seminari Alkitab Asia Tenggara, 2013), 395-398.
} 
lebih berpola spiral yang progresif sifatnya. Namun, tetap diperlukan suatu stuktur yang berguna untuk memberi gambaran yang komprehensif mengenai isi surat ini.

Menurut Tenney, struktur atau ikhtisar surat ini adalah sebagai berikut: ${ }^{11}$

Tema: Kepastian akan Kehidupan Kekal

I. Pembukaan: Perwujudan Sejarah Kehidupan 1:1-4

II. Kepastian Melalui Berjalan di dalam Terang 1:5-2:29

Dalam Sikap Rohani Pribadi 1:5-26

Dalam Hubungan Kemasyarakatan 2:7-11

Dalam Memisahkan Diri dari Dunia ini $\quad$ 2:12-17

Dalam Berpegang dalam Kebenaran 2:18-29

III. Kepastian Melalui Tinggal di Dalam Kasih 3:1-4:21

Bukti Etika dari Kasih 3:1-12

Bukti Sosial dari Kasih 3:13-24

Bukti Teologis dari Kasih 4:1-6

Bukti Emosi dari Kasih 4:7-21

IV. Kepastian melalui Perbuatan Iman $\quad$ 5:1-12

V. Penutup 5:13-21

Penulis sendiri mengusulkan sebuah struktur sebagai berikut:

I. Dasar pengajaran dan nasihat yang diberikan dan tujuan

penulisan surat 1:1-4

II. Pernyataan kebenaran yang utama: Allah adalah

Terang dan Kebenaran 1:5-10

Pengajaran mengenai Kristus: Kristus sebagai Pengantara 2:1-5

III. Nasihat untuk hidup dalam Kasih (1) : Mengasihi Sesama

dan mengasihi Tuhan

IV. Peringatan mengenai ajaran sesat (l): Anti-Kristus $\quad$ 2:18-27

V. Nasihat untuk hidup sebagai Anak-anak Allah 2:28-3:10

VI. Nasihat untuk hidup dalam kasih (2) 3:11-18

VII. Pengajaran mengenai Keyakinan akan Allah $\quad 3: 19-24$

VIII. Peringatan mengenai ajaran sesat (2): Anti-Kristus 4:1-6

IX. Nasihat untuk hidup dalam kasih (3) 4:7-21

$X$. Pengajaran mengenai iman dan keyakinan akan

Anak Allah 5:1-5

XI. Pengajaran mengenai keyakinan akan hidup yang kekal 5:6-21

Berdasarkan struktur di atas, dapat dilihat bahwa surat ini sangat menekankan tentang keyakinan akan Kristus sebagai Pengantara, Anak Allah dan jaminan keselamatan bagi orang percaya serta perlunya hidup

\footnotetext{
${ }^{11}$ Merril C. Tenney, Survey Perjanjian Baru (Malang: Gandum Mas, 2003), 467.
} 
dalam kasih sebagai tanda/ciri khas kehidupan anak-anak Allah. Kedua tema besar ini dibahas secara progresif seperti sebuah spiral; yang selalu berkaitan antara satu dengan lainnya. Yang satu menjadi dasar bagi yang lain dan yang lain tidak dapat dilepaskan dari yang satu itu. Gaya pembahasan Yohanes juga mungkin dapat digambarkan seperti orang yang merenda, mengaitkan benang renda sedemikian rupa berbolakbalik, terlihat seperti tumpang tindih, tetapi sebenarnya menghasilkan suatu rajutan yang sungguh menawan dan kuat.

\section{Analisis Kata men̄̄ dalam Surat 1 Yohanes}

\section{Metode Analisis}

Ada berbagai pola studi eksegesis yang telah dikembangkan oleh para ahli biblika. Salah satunya adalah yang dikemukan oleh Milton S. Terry dalam bukunya Biblical Hermenutics. ${ }^{12}$ Pada dasarnya, studi eksegesis tidak lepas dari analisis leksikal, analisis gramatikal, analisis konteks dan analisis historis. Prinsip-prinsip dasar inilah yang penulis terapkan dalam analisis bagian ini. Penulis juga mempertimbangkan dan mengkolaborasi prinsip-prinsip umum hermeneutik dan eksegese, termasuk yang khusus yang berkaitan dengan Perjanjian Baru seperti yang dikemukakan oleh Gordon D. Fee dalam bukunya New Testament Exegesis. ${ }^{13}$ Pandangan-pandangan D. A. Carson dalam bukunya Exegetical Fallacies $^{14}$ menjadi rambu-rambu bagi penulis dalam melakukan analisis ini. Oleh sebab itu, agar pembahasan kajian ini konsisten, penulis menyusun poin-poin studi eksegesis yang ditempuh dalam bagian ini sebagai berikut: Analisis Leksikal (uraian tentang primary meaning of words serta variasi penggunaan kata dimaksud), Analisis Gramatikal (uraian tentang bentuk-bentuk gramatikal kata tersebut) dan Analisis Konteks (bagaimana makna kata tersebut dalam konteksnya), dan Analisis Historis (menelusuri perkembangan kata dalam konteks sejarah).

\section{Analisis Leksikal}

\section{Kata men̄̄ dalam Alkitab}

Kata menō berarti to remain in a place, to tarry sebagai lawan dari to go away. ${ }^{15}$ Kata ini juga berarti await, remain, lodge, sojourn, dwell, continue,

\footnotetext{
${ }^{12}$ Milton S. Terry, Biblical Hermeneutics: A Treatise on The Interpretation of The Old and New Testaments (Grand Rapids: Zondervan Publishing House, 1974), 173-174;203-209.

${ }^{13}$ Gordon D. Fee, New Testament Exegesis (Kentucky: John Konx Press, 2002)

${ }^{14}$ D. A. Carson, Exegetical Fallacies (Grand Rapids: Baker Book House, 1996), 10-67.

15 TDNT, 574-575. Dalam Kejadian 24:55 (LXX) kata ini memiliki arti "tinggal di dalam rumah". Pada umumnya, LXX menggunakan kata ini dengan arti to last, to remain, to endure, to remain alive.
} 
endure. ${ }^{16}$ Kata menō bila digunakan untuk manusia atau benda menunjuk kepada suatu keadaan atau posisi tertentu yang tidak berpindah atau bergerak atau beranjak. Sementara ketika digunakan dalam hubungannya dengan Allah, kata ini dipakai untuk menunjukkan sifat Allah yang tidak berubah-ubah. Sifat ini adalah sifat Allah yang incomunicable. Allah adalah Allah yang tetap dalam janji dan firman-Nya. Ia adalah Allah yang setia dari kekal sampai kekal.

Secara umum, Perjanjian Baru menggunakan kata menō untuk: Ini berarti, kata ini ketika digunakan dalam hubungan dengan Allah, berarti menekankan sifatnya, sementara dalam hubungan dengan doktrin Kristen, kata ini digunakan secara kiasan menunjuk kepada ketetapan hidup sebagai umat yang diselamatkan. ${ }^{17}$ Akan tetapi, dalam Injil-injil dan Kisah Para Rasul, kata ini lebih sering digunakan dalam pengertian literal yaitu yang juga digunakan dalam Perjanjian Lama; tinggal dalam suatu tempat tertentu dalam arti sebenarnya seperti di rumah (lih. Luk. 8:27; 24:29; Kis. 28:16). Sedangkan dalam Surat-surat Kiriman kata ini lebih banyak digunakan dalam konteks kiasan dari pada harfiah, berkaitan dengan pengajaran mengenai iman, keselamatan dan kehidupan Kristen.

\section{Kata menō dalam tulisan-tulisan Yohanes}

Kata menō termasuk salah satu kata yang menjadi karakter tersendiri dalam tulisan-tulisan Yohanes. Kata ini digunakan 118 kali dalam seluruh Perjanjian Baru, sekitar 71 kali dalam tulisan-tulisan Yohanes; 40 kali dalam Injil Yohanes, 24 kali dalam surat 1 Yohanes dan 3 kali dalam surat 2 Yohanes, 1 kali dalam kitab Wahyu. Dari fakta ini dapat dikatakan bahwa Yohanes memiliki perhatian tersendiri dalam penggunaan kata ini. Yohanes sanggup menggunakan dan menempatkan suatu kata yang kelihatannya hanya kata biasa menjadi kata yang penting dan bermakna sesuai dengan tujuan dan maksud tulisannya yang mulia.

John Hepp menunjukkan dua kecenderungan penggunaan kata menō dalam Perjanjian Baru, dan bagaimana tulisan-tulisan Yohanes sendiri menggunakan kata itu. Ia menjelaskan bahwa:

Menō simply means "to stay, remain, continue" in a place, condition, or existence. Most writers use it only in literal sense: for physical or mental remaining. We will call this literal sense "sense A." John, however also

\footnotetext{
${ }^{16}$ International Standard Bible Encyclopaedia, Electronic Database Copyright (c)1996 by Biblesoft. Selanjutnya, ditegaskan pula bahwa "In the OT the abiding of God and the thing and persons relating to God is of religious and theological significance. As distinct from the imutability and transitoriness of everything earthly and human, God is characterised by the fact that He endure."

${ }^{17}$ International Standard Bible Encyclopaedia, 575-576.
} 
use meno in a non-literal sense for a moral or spiritual remaining. We will call this -"sense B." in either sense, meno extends an activity or status that already exists; it does not start a new one. For example, to stay in a place only extends being there; it is not a special kind of relationship... Every New Testament use of menō outside of John's writing is in sense A. John also sometimes uses it that way, as in the following examples from his Gospel... Now consider to sense B, to continue morally or spiritually. Over half the time in his Gospel and usually ih his epistle, John uses menō this way. ${ }^{18}$

Dari kutipan di atas dapat dipahami bahwa Yohanes menggunakan kata menō lebih sering dan lebih luas dalam tulisan-tulisannya. Ia tidak saja menggunakan kata ini dalam pengertian dasarnya tetapi juga mengembangkannya sedemikian rupa sehingga kata tersebut memberi pemahaman rohani yang lebih dalam bagi orang-orang percaya.

Tidak dapat dipungkiri lagi bahwa Yohaneslah satu-satunya penulis Perjanjian Baru yang menggunakan kata menō paling banyak dan paling luas dalam tulisan-tulisannya. Mengacu pada fakta ini, kata menō dalam tulisan-tulisan Yohanes menjadi menarik dan penting untuk dipelajari dan didalami. Pendalaman dan pemahaman yang baik melalui penggunaan kata ini dalam setiap konteksnya akan menolong orang percaya untuk kuat dalam kebenaran Kristiani, memiliki keyakinan yang pasti akan Kristus, dan hidup sebagai umat yang diselamatkan.

Bagi Yohanes, kata menō dapat menjelaskan bukan saja pengertian literal mengenai suatu peristiwa atau keadaan, tetapi juga menjelaskan suatu hubungan yang pasti yang terjadi antara satu pihak (seseorang) dengan pihak lain. Penggunaan menō dalam tulisan-tulisan Yohanes mencakup hal-hal tersebut, yang menjadi dasar penting dalam ajaran dan praktik hidup Kristen. Penggunaan kata ini dalam Injil Yohanes 1:38-39 telah menimbulkan pertanyaan apakah yang dimaksud menyangkut ranah fisik atau ranah rohani telah menjadi problematika tersendiri bagi para penafsir. Sebagian besar cenderung pada pengertian yang terakhir sementara bagi yang lain, konteksnya tidak menunjukkan demikian. ${ }^{19}$

\section{Analisis Gramatikal}

\section{Meno dalam Bentuk Present Active Indicative}

Kata menō dalam bentuk present active indicative merupakan bentuk tenses yang paling banyak digunakan dalam surat 1 Yohanes. Bentuk

18 John Hepp, "Meno and The Doctrine of Abiding," Diakses 21 Maret 2015, http://www.kingdominbible.com/assets/Abiding.pdf.

${ }^{19}$ Lihat Grant S. Osborne, Spiral Hermeneutika: Pengantar Komprehensif bagi Penafsiran Alkitab (Surabaya: Momentum 2012), 113. 
tenses ini digunakan $18 \mathrm{kali}$ dalam surat tersebut. Bentuk menei $\left(3^{\text {rd }}\right.$ person singular) digunakan sebanyak $15 \mathrm{kali}$, bentuk menomen ( $1^{\text {st }}$ person plural) 1 kali, bentuk menete ( $2^{\text {nd }}$ person plural) 2 kali. Mengingat karakter sastra surat ini yang bersifat paranese indicative, penggunaan tenses semacam ini semakin memperkuatnya.

Bentuk present active indicative adalah bentuk tenses yang menekankan pada tindakan yang dilakukan sedang dilakukan, atau peristiwa yang sedang berlangsung. ${ }^{20}$ Modus indicative merupakan pernyataan secara objektif dari suatu pekerjaan, atau tindakan atau perbuatan ataupun peristiwa. ${ }^{21}$ Bentuk ini dikenal juga dengan istilah linier (suatu tindakan progresif atau kegiatan yang terus menerus). ${ }^{22}$ Dengan demikian, maka bentuk present active indicative adalah bentuk yang menyatakan bahwa suatu tindakan (peristiwa) sedang terjadi, subjeknya melakukannya secara aktif dan tindakan/peristiwa itu merupakan suatu realitas.

Penulis surat 1 Yohanes menggunakan tenses sebanyak ini dalam tulisannya mengindikasikan bahwa apa yang dinasihatkan kepada pembacanya seharusnya menjadi suatu tindakan yang sifat realitas, bukan sebuah kemungkinan atau berandai-andai saja. Tersirat pula kesan bahwa apa yang dikatakan (seperti mengasihi sesama) seharusnya menjadi tindakan yang terus berlangsung, suatu tindakan yang sifatnya progresif. Tindakan-tindakan semacam itu harus menjadi fakta realitas yang objektif.

Ayat-ayat yang menggunakan bentuk ini merujuk kepada implikasi rohani dari hubungan seseorang dengan Allah (vertikal) dan kemudian hubungannya dengan sesamanya (horizontal). Paling banyak dipakai dalam hubungan dengan Allah (2:10, 27;3:9, 17, 24;4:12, 15-16). Satu ayat yang menyatakan keadaan, yaitu "tetap di dalam maut" di mana ini dihubungkan pada tindakan mengasihi sesama. Orang yang tidak mengasihi dianggap sebagai orang yang belum berpindah hidupnya dari maut ke dalam hidup.

\section{Men̄̄ dalam Bentuk Participle}

Kata menō dalam bentuk participle digunakan sebanyak 3 kali dalam surat 1 Yohanes, yaitu dalam ayat pasal $3(3: 6,15)$ dan pasal 4 (4:16). Ketiga ayat ini menggunakan meno dalam bentuk participle dengan infleksi

\footnotetext{
${ }^{20}$ Ruth Schäffer, Belajar Bahasa Yunani Koine: Panduan Memahami dan Menerjemahkan Teks Perjanjian Baru (Jakarta: BPK Gunung Mulia, 2013), 9.

${ }^{21}$ Ferdinan K. Suawa, Memahami Grammatika Dasar Bahasa Yunani Koine (Bandung: Yayasan Kalam Hidup, 2009), 38. 1988), 12.

22 Ray Summers, Yang Pokok dalam Bahasa Yunani Perjanjian Baru (Yogyakarta: STII,
} 
kata menōn (2 kali, 3:6 dan 4:16) menousan (1 kali, 3:15). Menurut Nathan E. Han, participle $e^{23}$ mengikuti sifat kata benda dengan memiliki deklensi, disertai objek, kata keterangan dan sebagainya. ${ }^{24}$ Tense participle dalam bahasa Yunani hanya ada empat yaitu present, aorist, future dan perfect. Present participle menyatakan tindakan yang terjadi bersamaan waktu dengan tindakan kata kerja pokok, aorist participle menyatakan tindakan yang mendahului kata kerja pokok, future participle menyatakan tindakan yang terjadi mengikuti (sesudah) tindakan kata kerja pokok, dan perfect participle menyatakan tindakan yang menjelaskan keadaan sesuatu. ${ }^{25}$

Surat 1 Yohanes menggunakan kata menō dalam bentuk present participle. Ini berarti bentuk kata ini menekankan bahwa pada waktu yang sama terjadi tindakan yang sama antara apa yang dilakukan kata kerja dengan tindakan yang dinyatakan dalam bentuk participle. Dalam pasal 3:6, participle menō menyatakan bahwa orang yang tetap tinggal di dalam Allah tidak berbuat dosa lagi (dan seterusnya). Berdasarkan penggunaan participle maka tindakan tinggal di dalam Dia seharusnya tidak berbuat dosa. Tidak jarang penekanan pada kata ho hamartanōn dalam bentuk present ditonjolkan karena alasan dogmatis (tidak berdosa terus-menerus). Pandangan seperti ini bisa saja mungkin, mengingat bentuk gramatikalnya memang demikian, tetapi harus juga dimaknai pada kalimat selanjutnya bahwa pada saat yang sama subjek juga disebutkan “... tidak melihat dan mengenal Dia”. Sementara itu 4:16 tidak menghubungkannya dengan dosa tetapi menekankan hubungan dengan Allah dan Allah di dalam orang itu.

Di bagian lain dalam 3:15 digunakan bentuk participle accusative singular feminim. Nas ini dikaitkan dengan tindakan membenci saudara, bahwa seseorang yang membenci saudara adalah seorang pembunuh dan bahwa seorang pembunuh tidak tetap memiliki hidup yang kekal di dalam dirinya. Dalam ayat ini pengenaan participle berada dalam frasa "tidak ada seorang pembunuh yang tetap memiliki hidup yang kekal dalam dirinya." Bentuk akusatif adalah bentuk objek langsung atau penderita langsung. Dapat dikatakan nas ini mengindikasikan bahwa seorang pembunuh tidak memiliki keyakinan yang tetap akan hidup yang kekal. Dalam konteks lengkapnya, membenci saudara berarti

${ }^{23}$ Nathan E. Han, A Parsing Guide to The New Testament (Scottdale, Pensylvania: Herald Press, 1994), 15. Kata menōn merupakan participle present active moninative singular masculine, sedangkan kata meousan merupakan participle present active accusative singular feminime. Participle adalah a verb adjective in addition to its characteristic as a verb.

${ }^{24}$ Ruth Schäuffer, Belajar Bahasa Yunani Koine: Panduan Memahami dan Menerjemahkan Teks Perjanjian Baru, 212. Biasanya participle diingkari dengan kata ingkar kata Yunani mê.

${ }^{25}$ Summers, 95. 
membunuh dan bagi seorang pembunuh ia tidak memiliki ketetapan keyakinan akan hidup yang kekal atau lebih tepatnya keraguan akan mengacaukan dirinya karena tindakannya itu.

\section{Men̄̄ dalam Bentuk Infinitive}

Dalam surat Yohanes, menō hanya sekali digunakan dalam bentuk infinitive. Kata ini terdapat dalam ayat 6 pasal 2, "Barangsiapa mengatakan, bahwa ia ada di dalam Dia, ia wajib hidup sama seperti Kristus telah hidup." ${ }^{26}$ Dari terjemahan ini dapat diketahui bahwa LAI menerjemahkan kata meno dengan arti "ada." Terjemahan KJV memakai kata "abide." Dalam hal ini, terjemahan KJV cukup baik dengan kata abide, karena menerangkan suatu keadaan yang tetap dan tidak berpindahpindah.

Dalam surat 1 Yohanes 2:6 bentuk infinitive yang dipakai adalah present active infinitive, yaitu menein. Ini berarti penulis surat 1 Yohanes menekankan aspek berulang atau terus menerus dari kata yang digunakan. Artinya, Yohanes hendak menyatakan bahwa seseorang yang percaya yang tetap/berada di dalam Kritus terus menerus/berkelanjutan, bukan sebentar saja (momentary).

\section{Men̄̄ dalam Bentuk Pluperfect}

Tense pluperfect untuk kata menō dalam surat 1 Yohanes digunakan satu kali. Bentuk ini digunakan satu kali dalam pasal 2:19, di mana kata yang dimaksud dalam hal ini adalah kata memenêkeisan. Kata menō dengan bentuk seperti ini hanya digunakan satu kali dalam seluruh Perjanjian Baru, yaitu di dalam surat 1 Yohanes ini.

Menurut Wenham, arti tense pluperfect juga serupa dengan arti tense perfect, hanyalah baik apa yang dilakukan itu maupun keadaan yang diakibatkannya dianggap sudah selesai (semuanya pada waktu lampau). ${ }^{27}$

26 Bentuk infinitive adalah sebuah nomina verba, yang tidak mempunyai subjek, tetapi sering ada sebuah kata dalam akusatif yang berfungsi seolah-olah ia adalah subjeknya. Infinitive dapat digunakan dengan lima cara, dan infinitive sering menyempurnakan sebuah ide yang penting.

${ }^{27}$ J. W. Wenham, Bahasa Yunani Koine (Malang: SAAT, 1987), 123. Terkadang dalam hasil penerjemahan, tidak mudah membedakannya dengan tense aorist. Untuk itu, seorang penerjemah harus memperhatikan dengan baik signifikansi dari kedua tenses ini agar sedapat mungkin dibuat terjemahan yang paling dekat dengan arti dimaksud. Dalam nas ini, dikatakan bahwa "Memang mereka berasal dari antara kita, tetapi mereka tidak sungguh-sungguh termasuk pada kita; sebab jika mereka sungguhsungguh termasuk pada kita, niscaya mereka tetap bersama-sama dengan kita...." (LAI). Kata memenêkeisan diterjemahkan dengan frasa "... niscaya mereka tetap bersamasama..." Terjemahan KJV berbunyi: “... they would no doubt have continued with us." 
Berdasarkan tense pluperfect, kalimat ini mengandung makna bahwa mereka (yang menyangkal Kristus) dulu adalah bagian dari anggota umat Tuhan dan selama kurun waktu tertentu, tetapi kurun waktu itu telah lewat dan mereka tidak lagi menjadi anggota dari persekutuan umat saat itu. Semuanya itu telah terjadi pada waktu lampau. ${ }^{28} \mathrm{Hal}$ ini cocok dengan penjelasan kalimat berikutnya "Tetapi hal itu terjadi, supaya menjadi nyata, bahwa tidak semua mereka sungguh-sungguh termasuk pada kita."

\section{Men̄̄ dalam Bentuk Imperative}

Bentuk imperative dari kata menō juga digunakan hanya sekali dalam surat 1 Yohanes. Kata menō dalam bagian ini terdapat dalam 1 Yohanes 2:24 yang digunakan sebanyak 3 kali dalam bentuk imperative (Yunani: menetō), aorist subyungtif (Yunani: meinê), dan future active indicative (Yunani: meneite). Tidak ada cara lain yang lebih kuat dalam bahasa Yunani untuk mengatakan kepada seseorang agar melakukan sesuatu, dari pada sebuah imperatif sederhana. Ketika perintah itu diberikan berkaitan dengan situsi tertentu orang yang memberikan perintah tersebut memandang dirinya sendiri sebagai figur yang berkuasa yang mengharapkan mereka yang disapanya melakukan dengan tepat seperti yang ia perintah. ${ }^{29}$

Dalam surat 1 Yohanes, bentuk imperative ini digunakan dalam frasa "Dan kamu, apa yang telah kamu dengar dari mulanya, itu harus tetap tinggal di dalam kamu." Nas ini berbicara tentang pembaca surat ini yang telah mendengar kebenaran Kristen sebelumnya, sehingga penulis surat ini menyatakan suatu bentuk imperative agar kebenaran itu tetap tinggal di dalam kehidupan mereka. Bagi penulis surat 1 Yohanes, hal ini sangat penting dan tidak bisa ditawar-tawar sehingga ia menggunakan bentuk tenses yang dengan kuat dan meyakinkan untuk melakukan hal tersebut.

\section{Men̄̄ dalam Bentuk Aorist Subyungtive}

Penggunaan aorist subyungtive dari kata menō dalam surat 1 Yohanes terdapat dalam 1 Yohanes 2:24, "Jika apa yang telah kamu dengar dari

\footnotetext{
${ }^{28}$ Bandingkan dengan penggunaan kata ebeblhto (diletakkan) dalam kisah Lazarus (Luk. 16:20).

29 Mounce, Basic, 254. Bandingkan Ernest D. Burton, Moods and Tenses of New Testament Greek, (Chicago: Chicago University, 1987), 89. Sementara itu, menurut Burton, tense imperative is used in commands, exhortations, entreatise and petitions, and also used to express consentor merely to propose an hypothesis. Any tense in imperative may be used in positive commands, on the other hand, the use of the imperative is confined almost entirely to the Present tense.
} 
mulanya tetap tinggal di dalam kamu...." ${ }^{30}$ Aorist subjungtive dibentuk dari stem kala aoris tak ber-augment; aspek adalah satu-satunya yang penting. Subjungtive tidak menggambarkan apa adanya, tetapi bagaimana seharusnya. Dengan kata lain, ini bukanlah modus mengenai realita tetapi mengenai kemungkinan (probabilitas). ${ }^{31}$

Berdasarkan prinsip gramatikal di atas, maka kalimat "Jika apa yang telah kamu dengar dari mulanya tetap tinggal di dalam kamu" utamanya bukan memberi kesan prasyarat, tetapi menekankan apa yang seharusnya. Keharusan sebagai kemungkinan yang semestinya mendapat perhatian atau tekanan dua kali dalam bagian ini dengan penggunaan imperative dan subjungtive. Penulis surat ini menyatakan dengan serius bahwa hal yang paling mungkin bagi seseorang untuk tinggal dalam Anak dan Bapa adalah harus tetap tinggal di dalam firman yang "telah kamu dengar dari mulanya."

\section{Analisis Konteks}

Analisis konteks ${ }^{32}$ yang dimaksud di sini adalah analisis setiap ayat mengacu pada konteks di mana ayat itu berada. Dalam ilmu Hermenutik dan atau eksegesis, konteks dapat dipahami sebagai, pertama, konteks kitab yang di dalamnya berbicara mengenai latar belakang kitab secara keseluruhan dan kedua, konteks di mana kata atau frasa atau bahkan ayat itu berada. ${ }^{33}$ Analisis konteks berfokus pada bagian yang berdekatan dengan ayat-ayat yang ditafsir, karena tidak ada penafsir yang dapat menjelaskan suatu bagian Alkitab tanpa memerhatikan konteks. Pemaparan analisis dalam bagian ini mengklasifikasikan kesamaan konteks ayat di mana kata menō terdapat di dalamnya.

Dengan memerhatikan struktur surat 1 Yohanes ini, maka pokok yang sering dibicarakan dalam surat ini adalah berkaitan dengan hubungan dengan Kristus dan hubungan dengan sesama. Nas-nas yang menggunakan kata menō pun berbicara selalu dalam hal sama, yakni

${ }^{30}$ Scauffer, 117-120. Terjemahan KJV berbunyi: "If that which ye have heard from the beginning shall remain in you..." Tense aorist adalah tense yang menyatakan perbuatan atau peristiwa terjadi secara sesaat, dipakai untuk mengekspresikan perbuatan atau peristiwa yang ingresif (diawali), efektif (diselesaikan) dan kompleksif (dipandang sebagai kesatuan). Terjemahan KJV berbunyi: "If that which ye have heard from the beginning shall remain in you..."

${ }^{31}$ Mounce, 236-237.

32 Konteks berasal dari dua kata Latin, yaitu con (yang berarti "bersama-sama" atau "menjadi satu") dan textus (yang berarti "tersusun"). Lihat Walter C. Kaiser, Toward an Exegetical Theology (Grand Rapids: Baker Book House, 1981), 71.

${ }^{33}$ Hasan Susanto memakai istilah "konteks dekat" dan "konteks jauh" untuk kedua hal ini. Lihat Hasan Sutanto, Hermeneutik: Prinsip dan Metode Penafsiran Alkitab (Malang: Literatur SAAT, 2011), 299. 
bagaimana hubungan pribadi anak-anak Tuhan dan bagaimana implikasi hubungan itu dalam hubungannya dengan sesama. Kedua bentuk hubungan ini selalu berkaitan dan saling berdampak antara yang satu dengan yang lainnya.

Konteks pertama dari kata menō adalah berbicara mengenai hubungan antara orang percaya dengan Tuhan, yang diukur dalam perspektif orang percaya terhadap firman Tuhan. Dalam hal ini menō digunakan dalam konteks ketaatan orang percaya dalam melakukan firman Tuhan. Pasal 3:24 dengan sangat jelas menunjukkan bahwa setiap orang yang menuruti firman Tuhan, "ia diam di dalam Allah" (Yunani: en autō menei) dan "Dia di dalam kita" (Yunani: menei en hêmin). Kehadiran Allah ini direpresentasikan dalam "Roh (Yunani: pneumatos) yang telah Ia karuniakan kepada kita."

Dalam cakrawala hubungan antara firman Allah dengan orang percaya, ayat lain yang berbicara 2:14. Dalam bagian ini dinyatakan bahwa "firman Allah diam di dalam kamu" dengan konteks khusus "kamu" yaitu orang-orang muda. Orang-orang muda yang dimaksud mungkin adalah orang-orang yang lebih muda, di mana kekuatan yang menjadi ciri khas mereka diperlukan untuk mengalahkan yang jahat. ${ }^{34}$ Tingkatan usia jasmani yang digunakan di sini dipakai sebagai analogi untuk tingkat kedewasaan rohani yang ada dalam jemaat penerima surat ini.

Pentingnya pembaca untuk tetap tinggal di dalam firman Allah sebagai ukuran tinggal di dalam Allah dinyatakan dalam 2:24. Dalam bagian ini firman Tuhan yang telah diperdengarkan kepada pembaca surat ini diharapkan tetap tinggal di dalam mereka. Jika firman itu ada di dalam kehidupan mereka, maka itu menjadi suatu ukuran bahwa mereka tinggal di dalam Anak dan di dalam Bapa. Gambaran kehadiran Allah dan Kristus dalam ayat ini direpresentasikan dalam kehadiran firman dalam kehidupan orang percaya. Sejajar dengan ayat ini, ayat 27 dalam pasal yang sama juga mengindikasikan bahwa jika firman kebenaran itu ada dalam kehidupan mereka, maka mereka tidak perlu mendengar pengajaran lain (yang salah). Ayat ini menghubungkan konteksnya dengan pengajar sesat yang ajarannya adalah ajaran anti-Kristus.

Tetap tinggal di dalam firman memiliki dampak yang signifikan. Hal ini berkaitan erat dengan pengakuan terhadap Kristus sebagai Anak Allah (4:15), komitmen atau kesungguhan sebagai bagian dari komunitas umat Allah (2:19) dan keberanian untuk percaya dan tidak malu pada hari kedatangan-Nya (2:28). Mereka yang tidak tinggal di dalam firman (berpegang teguh pada firman) tidak akan dapat mengaku bahwa

\footnotetext{
${ }^{34}$ Charles F. Pfeiffer, Everett F. Harrison, Tafsiran Alkitab Wycliff Vol.3: Perjanjian Baru (Malang: Gandum Mas, 2001), 1045.
} 
Kristus adalah anak Allah. Mereka juga tidak dapat menjadi anggota komunitas Allah yang sejati. Orang yang di luar Kristus juga tidak memiliki keberanian untuk percaya dan untuk menghadapi hari kedatangan-Nya. Penghiburan yang indah terdapat dalam 2:17 di mana dikatakan bahwa "orang yang melakukan kehendak Allah tetap hidup selama-lamanya." Upah ketaatan pada firman adalah kehidupan yang kekal.

Konteks kedua dari penggunaan kata menō dalam surat ini adalah berkaitan dengan hubungan mereka (orang-orang yang tinggal di dalam firman atau di dalam Kristus) dengan sesamanya. Dalam hal ini, kata penting yang dipakai konteks ini adalah kasih. Ditegaskan pertama-tama bahwa mereka yang tinggal di dalam Dia "wajib hidup sama seperti Kristus hidup." Keseluruhan hidupnya adalah pernyataan kasih termurni dan sempurna yang pernah ada. Sama seperti Kristus hidup menyatakan kasih, orang yang tinggal di dalam Dia seharusnya demikian.

Mengasihi sesama (saudara) merupakan salah satu ciri khas orang yang tinggal di dalam terang, yang di dalamnya tidak ada kegelapan atau penyesatan (2:10). Dengan kata lain, salah satu bukti nyata orang yang hidup dalam terang adalah mengasihi saudaranya. Kasih kepada saudara juga merupakan bukti bahwa seseorang telah berpindah dari maut ke dalam hidup (3:14). Orang yang membenci saudaranya adalah orang masih hidup dalam maut (kegelapan) dan orang yang demikian tidak tetap memiliki hidup yang kekal di dalam dirinya (3:15). Begitu pula orang yang menutup matanya terhadap saudaranya yang menderita kekurangan tidak dapat mengatakan bahwa kasih Allah ada (tetap, tinggal) di dalam dirinya (3:17). Hanya dengan saling mengasihi, orang percaya dapat menunjukkan bahwa Allah tinggal di dalam mereka (4:12) dan mereka di dalam Allah $(4: 13,16)$.

Berdasarkan ayat-ayat di atas, dapat dikatakan bahwa dengan menggunakan kata menō, Yohanes menunjukkan bahwa aspek kasih merupakan hal yang sangat signifikan dalam kehidupan orang percaya. Dalam konteks ini, menō menjadi sebuah ungkapan yang penting di mana kehadiran Allah dan kehidupan seseorang diukur melalui implementasi kasih dalam realitas kehidupannya. Kasih bukanlah pernyataan katakata semata tetapi tindakan yang nyata. Orang yang tidak mengasihi diasosiasikan dengan kehidupan yang lama, di mana penyesatan (kegelapan), maut, dan ketidakpastian akan keselamatan menjadi hal yang tidak dapat dielakkan.

Akhirnya kata menō digunakan dalam kaitannya dengan (perilaku) dosa. Dikatakan bahwa "setiap orang yang tetap berada di dalam Dia tidak berbuat dosa lagi, sebab benih ilahi tetap ada di dalam dia" $(3: 6,9)$. Di sini yang ditekankan adalah suatu keadaan, di mana kehadiran ilahi menjadi sumber kekuatan untuk menjauhi dosa. Dilematika interpretasi 
sehubungan dengan hal ini banyak menyoroti bagaimanakah mungkin seseorang tidak dapat berdosa sama sekali setelah ia menjadi anak-anak Allah. Jawaban yang muncul dan yang paling sering diterima adalah bahwa bagian ini harus diartikan dengan tidak berdosa secara terus menerus (indikatif). Secara gramatikal, bisa saja berarti demikian, mengingat bentuk gramatikalnya mendukung. Tetapi pandangan ini akan cenderung memberi legitimasi pada tindakan dosa, hal mana yang mungkin tidak dimaksudkan penulis. Mengartikannya secara harafiah akan mengindikasikan suatu keadaan surgawi (yang jauh dari dosa), di mana Yohanes sesungguhnya tidak memaksudkan demikian (suatu keadaan yang sempurna tanpa dosa), tetapi ia hendak menunjukkan ketidakcocokan dari pada ketidakmungkinan seseorang berdosa. ${ }^{35}$ Pada hakikatnya, orang yang lahir dari Allah dan berada di dalam Dia memiliki potensi untuk menjauhkan diri dari dosa karena benih ilahi tinggal tetap di dalamnya dan karena mereka mengenal Dia.

\section{Analisis Historis}

Analisis historis pada bagian ini bertujuan untuk melihat korelasi dan signifikansi penggunaan kata menō dalam surat 1 Yohanes bagi pembacanya saat itu. Sebagaimana telah disebutkan bahwa surat 1 Yohanes ditulis bagi sejumlah jemaat di Asia, maka dengan demikian dapatlah dianalisis hubungan historis antara penerima surat ini dengan konten surat itu sendiri. Selain itu, melalui analisis ini juga dapat diperoleh gambaran mengenai penggunaan kata ini dalam keseluruhan konteks historis tulisan Yohanes. Agar pembahasan tidak meluas, maka dalam bagian ini penulis menyoroti eksistensi Johannine community dalam kaitan dengan konsep kata menō dalam surat 1 Yohanes.

Johannine Community adalah teori yang dikemukakan para ahli Perjanjian Baru bahwa ada suatu komunitas yang menjadi latar belakang utama dan sangat berperan/dominan di balik keempat tulisan Yohanes. Sarjana modern yang sangat populer dengan teori ini adalah Raymond E. Brown di mana ia memopulerkan teori ini lewat bukunya yang berjudul The Community of The Beloved Disciple. Selain itu ada juga ahli Perjanjian Baru lainnya seperti Georg Richter, Herman Hendrickx, David Rensberger dan Adele Reinhartz yang juga tertarik membahas teori yang sama walaupun dengan pendekatannya masing-masing.

Paul Anderson, profesor bidang studi Alkitab di George Fox University mengatakan bahwa Johannine Community adalah:

A network of churches located in Asia Minor responsible for the production of the four New Testament writings: the Gospel of John and the three letters

\footnotetext{
${ }^{35}$ Tafsiran Alkitab Masa Kini 3 (Jakarta: Yayasan Komunikasi Bina Kasih, 2012), 867.
} 
known as 1 John, 2 John and 3 John. Together those books reveals how a particular Christian community dealt with religious tensions during the last few decades of the first century. The Johannine community may have included Christians who migrated to Asia Minor from Palestine after the destruction of Jerusalem in 70 C.E. ${ }^{36}$

Kesan mengenai adanya suatu komunitas tersendiri yang ingin ditonjolkan dalam tulisan-tulisan Yohanes, terlihat dalam redaksi Injil Yohanes 1:19-29 dan 3:22-25. Dalam Injil Sinoptis, redaksi kemunculan Yohanes Pembaptis berkaitan dengan persiapan pelayanan Yesus dan pertobatan, sementara dalam Injil Yohanes lebih kepada pertanyaan mengenai apakah Yohanes Pembaptis adalah Mesias yang dijanjikan. Dalam pasal 3, tensi antara komunitas tersebut dengan Yudaisme terasa semakin meningkat. Dialektika antara komunitas khusus ini dengan komunitas lainnya seperti Yudaisme dan lainnya terasa dalam sepanjang narasi Injil Yohanes dan juga tulisan-tulisan Yohanes. ${ }^{37}$

Menurut Raymond Brown, sejarah perkembangan Johannine Community terbagi atas empat fase utama, yaitu Masa Awal (pertengahan tahun 50-80), Masa Injil (sekitar tahun 90), Masa Surat-surat (sekitar tahun 100), dan Masa sesudah Injil-Injil (sekitar abad II). Penjelasan mengenai hal ini disarikan di bawah ini: ${ }^{38}$

Fase Pertama, yaitu masa awal merupakan masa mula-mula lahirnya kelompok ini. Pada masa ini komunitas ini terdiri dari orang Yahudi, termasuk murid-murid Yohanes Pembaptis yang menerima Yesus tanpa keraguan sedikitpun. Di antara kelompok ini terdapat seseorang yang kemudian diperkenalkan sebagai "murid yang terkasih". Kelompok ini kemudian berkembang menjadi kelompok yang menempatkan Yesus sebagai Tuhan yang kemudian menimbulkan konflik dengan Yudaisme. Kelompok ini tetap mempertahankan keyakinan mereka dan dalam situasi ini "murid yang terkasih" memainkan perannya untuk benarbenar menyatakan Yesus sebagai Anak Allah, Mesias dan Juruselamat manusia.

Fase Kedua atau masa Injil merupakan masa di mana tensi dengan Yudaisme benar-benar memuncak. Akibatnya terjadi diaspora dan Yesus diberitakan keluar Palestina. Penolakan oleh orang Yunani dan

36 Paul Anderson, The Johannine Community, Diakses 2 April 2015, www.bible odyssey.org/en/people/ related-article/johannine-community.

37 Bdk. David L. Barr, "As the Father Has Sent Me": Community Dialogues in John 20, www.wright.edu/-dbarr/absart.htm Lihat juga Adele Reinhartz, The Johannine Community and its Jewish Neighbors: A Reappraisal, www.thefisherofmenministries.com/The $\% 20$ Johannine\%20Community\%20and\%20its\%20Jewish\%20Neighbors.pdf

38 Raymond E. Brown, The Community of The Beloved Disciple, www.institute ofchatolicculture.org/wp-content/uploads/2015/04/Brown-Johannine-Community.pdf. 
penganiayaan oleh orang Yahudi membawa komunitas ini meyakini bahwa mereka adalah pengikut Yesus yang sejati, Israel baru yang kemudian membentuk persekutuannya sendiri (gereja). Pada masa inilah mereka dikenal dengan sebutan Kristen yang artinya pengikut Kristus. Pada masa ini, pertentangan mengenai Yesus semakin kuat dan meningkat.

Fase Ketiga, yaitu Masa Surat-surat, perbedaan pandangan mengenai Yesus sudah tidak dapat dipersatukan lagi dengan cara apapun. Pada masa ini perpecahan terjadi, yaitu satu kubu yang mempertahankan pengajaran tentang Yesus sesuai dengan pengajaran para rasul dan satu kubu yang mencoba merumuskan Yesus menurut pemahaman pengetahuan dan filsafat manusia. Di sini terjadilah pembedaan antara mereka yang disebut "anak-anak Allah" dan mereka yang disebut "penyesat/bidat/sekte".

Masa Keempat yakni masa sesudah Surat-surat adalah masa di mana dua aliran yang terpecah tadi menempuh jalannya sendiri-sendiri. Kubu pertama bersatu dan membentuk gereja sebagai sebuah persekutuan umat (Chatolic Church), sementara yang lainnya menempuh jalan yang dikenal dengan Gnostisisme (yang di dalamnya terdapat docetisme, gnostisisme, montanisme, dan lain-lain).

Memerhatikan periodisasi yang dikemukakan Brown di atas, dapat dikatakan bahwa Johannine Community mengalami perkembangan sedemikian rupa yang pada akhirnya memperhadapkan mereka pada sebuah pilihan yaitu mempertahankan keyakinan akan Yesus melalui suatu komunitas orang percaya yang boleh disebut gereja. Banyaknya perdebatan mengenai Yesus sebagai pusat keyakinan dan pengajaran membuat komunitas ini harus mempertajamkan pemahaman mereka mengenai keilahian Yesus. Untuk tujuan pembedaan antara komunitas yang benar dan salah, maka, Johannine community is the community developed a strong dualistic against the world, and eventually against all those within their own community that disagreed with them. Everything was either black or white, good or evil, to the point that one could not even pray for those in the darkness. ${ }^{39}$

Tidak dipungkiri lagi bahwa polemik Kristologi merupakan problematika yang paling dominan dihadapi oleh komunitas ini. Kejatuhan Yerusalem disinyalir sebagai salah satu situasi yang menyebabkan krisis iman dan menimbulkan trauma serta pertanyaan krusial mengenai kepercayaan Kristen itu sendiri. Interpretasi mengenai ajaran Yesus menjadi penting di mana doktrin dan etika harus mendapat

39 Pat Perriello, Vatican II and The Lessons of The Johannine Community, www.ncronline.org/blogs/ncr-today/vatican-ii-and-the-lessons-johannine-communityhtm. 
fondasi yang kokoh. ${ }^{40}$ Tulisan-tulisan Yohanes jelas menunjukkan suatu pergumulan yang sifatnya internal maupun eksternal. Surat 1 Yohanes secara implisit menunjukkan pergumulan internal komunitas ini. ${ }^{41}$

Permasalahan mengenai Kristologi dan praktika hidup Kristen jelas terlihat dalam surat 1 Yohanes. Keilahian Kristus dan Kasih terhadap sesama merupakan pokok yang sering ditekankan dalam surat ini. Nasihat-nasihat Yohanes yang bersifat ke dalam menunjukkan bahwa secara internal komunitas Kristen pada saat itu sedang goncang sehingga mereka membutuhkan penguatan bagi diri mereka sendiri. Pengajaran mengenai hakikat dan karya Yesus ditekankan berulang, demikian pula dengan pengajaran tentang kasih.

Untuk menjawab dan mengantisipasi semua permasalahan dalam komunitas Kristen, termasuk komunitas ini, maka diperlukan paranese indikatif yang deliberatif sifatnya di mana keunggulan dan keotentikan ajaran Kristen dipertahankan. Penulis surat 1 Yohanes memilih menggunakan sebuah homili di mana fondasi iman Kristen dapat dijabarkan sedemikian rupa sehingga pengajaran sesat dapat dibendung dan kebenaran dapat tetap bertahan. Penggunaan kata menō dalam tulisan-tulisan Yohanes dapat dipahami untuk mencapai tujuan ini. Mengingat makna yang terkandung dalam kata ini, maka sejarah perkembangan komunitas Kristen dalam pergumulannya akan kebenaran di dalamnya telah terdapat indikasi yang kuat di mana kata menō menjadi salah satu kata penting yang digunakan untuk menjelaskan dasar iman dan keyakinana Kristen yang sejati.

Dengan demikian maka siginfikansi penggunaan kata menō dalam konteks historis berkaitan dengan Johannine community menunjukkan bahwa terdapat relevansi yang kuat. Penggunaan kata ini yang di dalamnya terkandung pengajaran dan nasihat yang mendasar mengenai doktrin dan praktika hidup Kristen jelas menunjukkan bahwa secara historis teologis kata ini merupakan kata yang penting dalam pergumulan iman dan perkembangan doktrin dalam komunitas Kristen perdana.

\section{Kesimpulan}

Perjanjian Baru menggunakan kata menō digunakan dalam hubungan dengan Allah, berarti menekankan sifatnya, sementara dalam hubungan dengan doktrin Kristen, kata ini digunakan secara kiasan menunjuk kepada ketetapan hidup sebagai umat yang diselamatkan.

\footnotetext{
${ }^{40}$ Herman Hendrickx, The Johannine Community, Theology Annual Vol. 12

${ }^{41}$ David Rensberger, Johannine Faith and Liberating Community (Philadelphia: Westminster Press, 1988), 41-48.
} 
Secara gramatikal, bentuk yang menyatakan bahwa suatu tindakan (peristiwa) sedang terjadi, subjeknya melakukannya secara aktif dan tindakan/peristiwa itu merupakan suatu realitas. Penulis surat ini, Yohanes menyatakan dengan serius bahwa hal yang paling mungkin bagi seseorang untuk tinggal dalam Anak dan Bapa adalah harus tetap tinggal di dalam firman yang "telah kamu dengar dari mulanya."

Sedangkan pendekatan analisis konteks arti menō adalah orang yang lahir dari Allah dan berada di dalam Dia memiliki potensi untuk menjauhkan diri dari dosa karena benih ilahi tinggal tetap di dalamnya dan karena mereka mengenal Dia.

Dalam konteks historis penggunaan kata menō yang di dalamnya terkandung pengajaran dan nasihat yang mendasar mengenai doktrin dan praktika hidup Kristen jelas menunjukkan bahwa secara historis teologis kata ini merupakan kata yang penting dalam pergumulan iman dan perkembangan doktrin dalam komunitas Kristen mula-mula.

\section{Kepustakaan}

Anderson, Paul. "The Johannine Community." Diakses 2 April 2015. http://www.bibleodyssey.org/en/people/related-article/johanninecommunity.

Barr, David L. "As the Father Has Sent Me": Community Dialogues in John 20. Diakses 2 April 2015. http://www.wright.edu/-dbarr/absart.htm.

Brown, Raymond E. "The Community of The Beloved Disciple." Diakses 2 April 2015. http://www.instituteofchatolicculture.org/wpcontent/uploads/2015/04/Brown-Johannine-Community.pdf.

Burton, Ernest D. Moods and Tenses of New Testament Greek. Chicago: Chicago University, 1987.

Carson, D. A. Exegetical Fallacies. Grand Rapids: Baker Book House, 1996.

Drane, John. Memahami Perjanjian Baru: Pengantar Historis - Teologis. Jakarta: BPK Gunung Mulia, 1996.

Elwell, Walter A. ed., Evangelical Dictionary of Theology. Michigan: Baker Book House, 1989.

Fee, Gordon D. New Testament Exegesis. Kentucky: John Konx Press, 2002.

Han, Nathan E. A Parsing Guide to The New Testament. Scottdale, Pensylvania: Herald Press, 1994.

Harrison, Everret F. Introduction to The New Testament. Michigan:Wm. B. Eerdmans Publishing Company, 1965.

Hayes, John dan Carl R. Holladay, Pedoman Penafsiran Alkitab. Jakarta: BPK Gunung Mulia, 1996.

Hendrickx, Herman. The Johannine Community. Theology Annual Vol. 12, 1990. 
Hepp, John. "Menō and The Doctrine of Abiding," diaskes 21 Maret 2015, http://www.kingdominbible.com/assets/Abiding.pdf.

Kaiser, Walter C. Toward an Exegetical Theology. Grand Rapids: Baker Book House, 1981.

Klein, William W., Craig L. Blomberg, and Robert L. Hubbard, Introduction to Biblical Interpretation. Malang: Literatur Seminari Alkitab Asia Tenggara, 2013.

Mounce, William D. Basics of Biblical Greek: Dasar-Dasar Bahasa Yunani Biblika. Malang: Literatur Seminari Alkitab Asia Tenggara, 2011.

Murray, Andrew. Tinggal di Dalam Kristus. Jakarta: Light Publishing, 2014.

Osborne, Grant S. Spiral Hermeneutika: Pengantar Komprehensif bagi Penafsiran Alkitab. Surabaya: Momentum 2012.

Perriello, Pat. "Vatican II and The Lessons of The Johannine Community.” Diakses 2 April 2015.http://

www.ncronline.org/blogs/ncr-today/vatican-ii-and-the-lessonsjohannine-community-htm.

Pfeiffer, Charles F., Everett F. Harrison, Tafsiran Alkitab Wycliff Vol.3: Perjanjian Baru. Malang: Gandum Mas, 2001.

Reinhartz, Adele. "The Johannine Community and its Jewish Neighbors: A Reappraisal." Diakses 2 April 2015.

http://www.thefisherofmenministries.com/The\%20Johannine\%20C ommunity\%20and\%20its\%20Jewish\%20Neighbors.pdf.

Rensberger, David. Johannine Faith and Liberating Community. Philadelphia: Westminster Press, 1988.

Ronda, Daniel. Dasar Teologi yang Teguh: Panduan Teologi Sistematika di Perguruan Tinggi. Makassar: Sekolah Tinggi Theologia Jaffray, 2013.

Schäffer, Ruth. Belajar Bahasa Yunani Koine: Panduan Memahami dan Menerjemahkan Teks Perjanjian Baru. Jakarta: BPK Gunung Mulia, 2013.

Sitompul, A. A. dan Ulrich Beyer, Metode Penafsiran Alkitab. Jakarta: BPK Gunung Mulia, 2012.

Suawa, Ferdinan K. Memahami Grammatika Dasar Bahasa Yunani Koine Bandung: Yayasan Kalam Hidup, 2009.

Summers, Ray. Yang Pokok dalam Bahasa Yunani Perjanjian Baru. Yogyakarta: STII, 1988.

Sutanto, Hasan. Perjanjian Baru Interlinear Yunani - Indonesia dan Konkordansi Perjanjian Baru: Jilid II: Konkordansi Perjanjian Baru. Jakarta: Lembaga Alkitab Indonesia, 2002.

Sutanto, Hasan. Prinsip dan Metode Penafsiran Alkitab. Malang: Literatur Seminari Alkitab Asia Tenggara, 2011.

Tafsiran Alkitab Masa Kini 3. Jakarta: Yayasan Komunikasi Bina Kasih, 2012. 
Tenney, Merril C. Survey PerjanjianBaru. Malang: Gandum Mas, 2003.

Terry, Milton S. Biblical Hermeneutics: A Treatise on The Interpretation of The Old and New Testaments. Grand Rapids: Zondervan Publishing House, 1974.

Wenham, J. W. Bahasa Yunani Koine. Malang: Literatur Seminari Alkitab Asia Tenggara, 1987. 